INDEPENDENT JOURNAL OF MANAGEMENT \& PRODUCTION (IJM\&P)

http://www.ijmp.jor.br $\quad$ v. 11, n. 5, Special Edition IFLOG 2019 -September 2020 ISSN: 2236-269X

DOI: 10.14807/ijmp.v11i5.1280

\title{
LEAN AND METROLOGY: A SYSTEMATIC REVIEW AND BIBLIOMETRIC ANALYSIS OF THE SCIENTIFIC LITERATURE FROM THE LAST 20 YEARS
}

\author{
Lucas França Tanaro \\ IFRJ, Brazil \\ E-mail: lucas.franca004@gmail.com \\ Heymert Vinícius Pacheco \\ IFRJ, Brazil \\ E-mail: heymert@gmail.com \\ Ana Carla de Souza Gomes dos Santos \\ IFRJ and CEFET/RJ, Brazil \\ E-mail: ana.carla@ifrj.edu.br \\ Letícia Ali Figueiredo Ferreira \\ CEFET/RJ, Brazil \\ E-mail: leticialifig@gmail.com \\ Genildo Nonato Santos \\ IFRJ, Brazil \\ E-mail: genildo.santos@ifrj.edu.br
}

Submission: 2/22/2020

Revision: 2/29/2020

Accept: 3/6/2020

\section{ABSTRACT}

The metrology area is responsible for measurement properties and is present in the market through services related to calibration, standardization, maintenance, measurement traceability, and certification. While there is a demand from metrology companies for efficient methods of managing the quality of their services and operations, lean culture encompasses the most important management techniques with applications in various segments. Considering the aspects that permeate these two areas, the question arises about a possible intersection between the demands of companies and metrology laboratories to remain competitive and certified in the market and benefits provided by lean culture. Thus, this paper performs a systematic review, according to the PRISMA protocol, in order to verify if there is an intersection between lean and metrology in the scientific literature. 
DOI: 10.14807/ijmp.v11i5.1280

Through bibliometric and qualitative analyses, the research shows a gap of application with a lack of articles in this area, as well as a great potential of places and tools to be implemented.

Keywords: metrology; lean; PRISMA

\section{INTRODUCTION}

Metrology is the area of expertise responsible for practical and theoretical properties related to measurement, helping to ensure the accuracy of its methods, equipment, techniques, products, and systems (PEDRAZA; MONTEALEGRE; SERREZUELA, 2018). In addition to its role as a science, it is also important to highlight the importance of metrology in a marketing context, given its relationship to quality management through providing comparability and traceability criteria in the measurement of end products and is commonly used in statistical process control (ARREDONDO-SOTO et al., 2018; KARTHIYAYINI; RAJENDRAN, 2017; WESTGARD; WESTGARD, 2017).

Several sectors in the economy, such as agroindustrial, automotive, metallurgical, electronic and clinical analysis use metrology to perform various services related to calibration, standardization, equipment maintenance, measurement traceability and certification (ARREDONDO-SOTO et al., 2018; GOMEZ; KREMER; SLEPETIS, 2017; STONE; MONTEALEGRE; SERREZUELA, 2018). Thus, metrology and calibration laboratories have a fundamental role in organizations, being responsible for verifying both product attributes (size, weight, accuracy, among others), as well as the authentication of measurements and adjustment of equipment present in their processes (ROUND SOTO et al., 2018).

Regarding the execution of these services, it is important to emphasize that they can be performed both by internal sectors in companies, which have metrology laboratories for their analysis of their products and processes, as well as by hiring outsourced laboratories. Thus, it is possible to find in the market companies whose focus is the provision of services related to the metrology area (BARRADAS; SAMPAIO, 2017; SILVA; RIBEIRO, 2019).

In Brazil, these companies are controlled and certified by INMETRO (National Institute of Metrology, Quality, and Technology). Data from the Brazilian Calibration Network state that there are about 428 duly certified calibrations and testing laboratories, of which 59 are in the state of Rio de Janeiro, concentrating the second largest quantity in the country (INMETRO, 2019). To guarantee the quality and reliability of the service provided, accreditation is a fundamental step (BARRADAS; SAMPAIO, 2017; INMETRO, 2019). Based on ISO 17025 
DOI: 10.14807/ijmp.v11i5.1280

and incorporating important aspects of ISO 9001, this accreditation ensures the competence not only of the measurement system but also of the professionals responsible (BARRADAS; SAMPAIO, 2017; INMETRO, 2019; KARTHIYAYINI; RAJENDRAN, 2017).

Thus, there is a demand from the metrology business to manage the quality of their services and operations, especially to meet market needs (BARRADAS; SAMPAIO, 2017). Among the benefits sought are the minimization of the risk of unreliable results, the minimization of rework (allowing the reduction of the quality cost), the national and international recognition of the results of the tests performed and the improvement in the efficiency and effectiveness of the processes performed in the laboratories (KARTHIYAYINI; RAJENDRAN, 2017).

In this context, it is emphasized that lean culture practices have shown interest in increasing organizational competitiveness through waste identification and elimination, process standardization and control, total quality management and preventive maintenance (BAI; SATIR; SARKIS, 2019 SILVA et al., 2019). Today, this culture encompasses the most important and popular management techniques, with well-established principles and a wide range of tools applied in various segments, such as health (KOVACEVIC et al., 2016), construction (KOSKELA et al., 2019; SARHAN et al., 2017), services (LEITE et al., 2015; RAUCH et al., 2016), education (BALZER et al., 2016; BALZER; BRODKE; KIZHAKETHALACKAL, 2015) and department stores (LEITE et al., 2015). Table 1 presents some positive results of lean application in different segments.

Table 1: Lean implementation contributions in different segments

\begin{tabular}{|c|c|}
\hline Segments & Positive results \\
\hline Health & $\begin{array}{l}\text { Up to } 50 \% \text { reduction in appointment waiting times and approximately } \$ 0.5 \text { million per year } \\
\text { decrease in intensive care unit costs (KOVACEVIC et al., 2016) }\end{array}$ \\
\hline Civil construction & About 77\% increase in quality and productivity in construction projects (KOSKELA et al., 2019) \\
\hline Education & $\begin{array}{l}\text { Reducing the time required to change the funding source for graduate students from } 20 \text { days to } 45 \\
\text { minutes, saving over } \$ 100,000 \text { in billing processes } \\
\text { KIZHAKETHALACKAL, 2015) }\end{array}$ \\
\hline Department store & Elimination of the need to keep inventory in the warehouse (LEITE et al., 2015) \\
\hline
\end{tabular}

From this information, we can see a possible interposition between the demands of companies and metrology laboratories to remain competitive and certified in the market and the benefits provided by lean culture. Based on this assumption, this paper raises the following question: Is there an exploration of the relationship between metrology and lean in the scientific literature and how is it built? 
DOI: 10.14807/ijmp.v11i5.1280

In addition to this introduction, this article describes the methodological steps in section 2, section 3 presents the results and discussions, and finally, section 4 highlights the conclusions.

\section{RESEARCH METHODOLOGY}

The protocol used to perform the systematization was defined and designed according to the Preferred Reporting Items for Systematic Reviews and Meta-Analyzes (PRISMA) (MOHER et al., 2009). Figure 1 presents the PRISMA Protocol used in the present study.

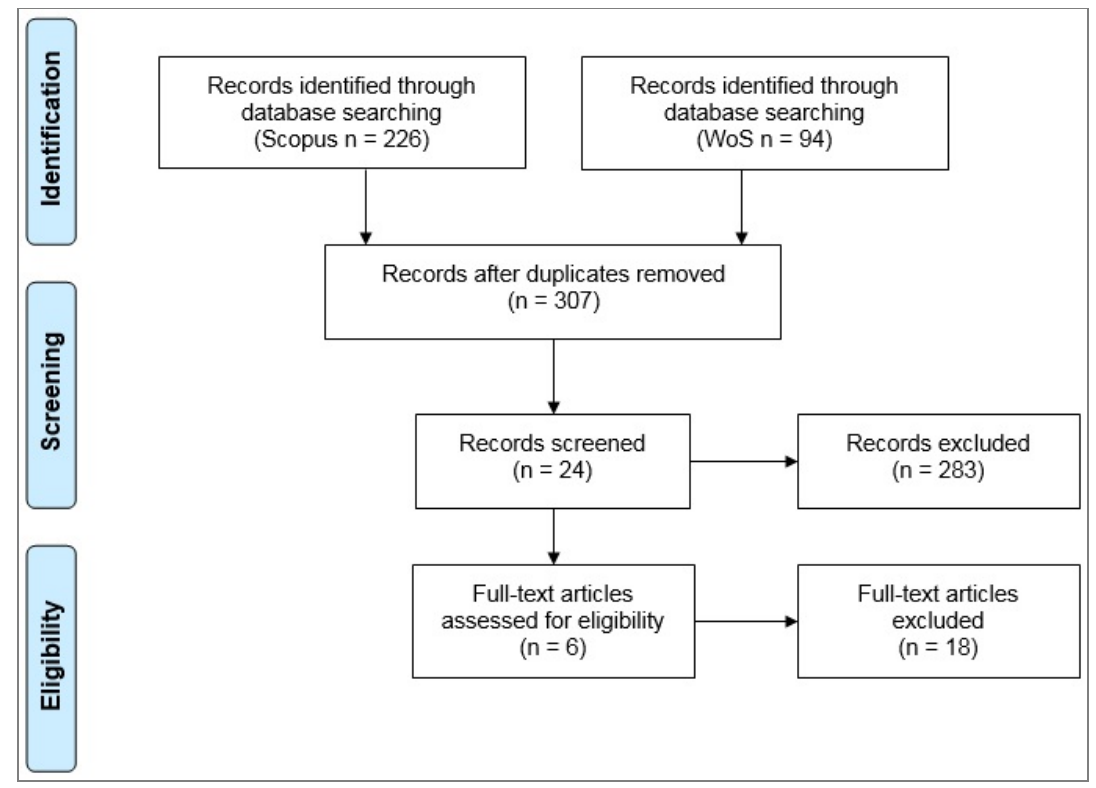

Figure 1: PRISMA Protocol

First, the specific expressions were defined to survey the articles that were at the intersection between lean and metrology, as shown in Figure 2. The search terms used were (Lean AND Metrolog*) and (("Lean manufacturing" OR "Lean management" OR "Lean system" OR "Toyota production system" OR "Lean philosophy" OR "Lean thinking" OR "Lean methodology") AND (Calibrat* OR Metrolog* OR Laborator*)).

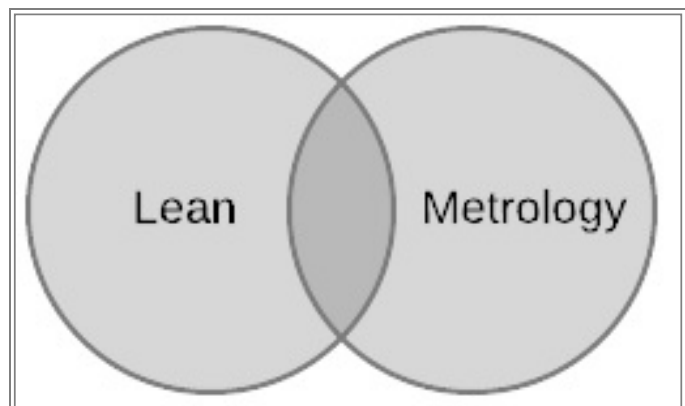

Figure 2: Venn diagram of the intersection between Lean and Metrology 
DOI: 10.14807/ijmp.v11i5.1280

Such search expressions were established from a dynamic reading of scientific articles on lean or metrology. The search for similar terms, initially, was not intended to identify articles that had both themes simultaneously in the same document, but rather what were the possible related nomenclatures that would allow a broader coverage at the time the base survey was performed.

The OR logical operator was used between two or more words to cover the different forms that are most explored in searches. The logical operator AND allowed the intersection between terms, excluding articles that were not adherent to the theme and the object of study. Using quotation marks allowed you to find terms exactly as they were defined, and the symbol $\left.{ }^{*}\right)$ made it possible to count any term prefixed with the preceding keyword.

The bases used were Web of Science (WoS) and Scopus. WoS for allowing access to over 12000 journals (COSTA et al., 2017) and being considered the largest authority in the scientific literature (YAN; LIAO; CHEN, 2018) and Scopus for being the largest bibliometric database (FILSER; SILVA; OLIVEIRA, 2017), both considered as the main standard citation bases (CISNEROS et al., 2018; MONGEON; PAULHUS, 2016; TUNGER; EULERICH, 2018).

In addition to the previously defined bases, the other inclusion criteria used to map the articles were the period of publication (last 20 years), language (English) and medium of publication (conference or magazine). Therefore, as can be observed in the PRISMA Protocol (Figure 1), from the search terms and the inclusion criteria established, 226 articles were identified in Scopus and 94 in WoS. Then, duplicate articles were removed, totaling 13 articles removed, and 307 articles remaining for the next step. Table 2 summarizes the search, inclusion and exclusion criteria.

Table 2: Inclusion and exclusion criteria

\begin{tabular}{lcc}
\hline \multicolumn{1}{c}{ Search criteria } & Inclusion & Exclusion \\
\hline Data base & Scopus e WoS & Other databases \\
Publication period & January de 2000 a August de 2019 & Articles published before or after the period \\
Idiom & English & Other languages \\
Means of publication & Conference or Journal & Books or chapters, notes, letters, dissertations and theses \\
\hline
\end{tabular}

The next step of the PRISMA Protocol, called selection, encompassed a dynamic reading of the title, abstract, and keywords to separate only articles that had adherence to the scope of this work. 283 were excluded, and 24 articles were selected. In the eligibility stage, the 24 articles were read in full, but only 6 addressed the intersection between lean and metrology. Then, a bibliometric analysis of the 6 selected articles was performed. Bibliometric analysis is used to measure and evaluate the scientific production of publications concerning a 
DOI: 10.14807/ijmp.v11i5.1280

topic of interest, as well as provide an understanding of the state of the art and highlight gaps in future research trends (FILSER; SILVA; OLIVEIRA, 2017).

The analyzes that were made concern the total publication per year; the total citation of articles according to each base; the types of approach (conceptual or applied), and; total publication, and citation total by publication medium (conference or magazine), affiliation, country, and subject area. Also, it was analyzed (qualitatively) the place of application in the company, tools, positive and negative results, facilitators, barriers, and factors that motivated the implementation.

\section{RESULTS ANALYSIS AND DISCUSSION}

The presentation of the results was divided into two distinct topics. Topic 3.1 presents the bibliometric indicators of the articles analyzed, and topic 3.2 presents the qualitative analysis of the articles found. This approach was used to get an overview of the main aspects of the discussion, as pointed out in the methodology.

\subsection{Bibliometric analysis}

The number of 6 articles evaluated as eligible evidence a noticeable gap regarding the intersection between lean and metrology. Considering the statistics presented for the annual production of articles (Figure 3), it is clear that in the last 20 years there has been a concentration of articles published only in the last decade, and an absence of publications in the years 2011, 2012, and between 2014 and 2017.

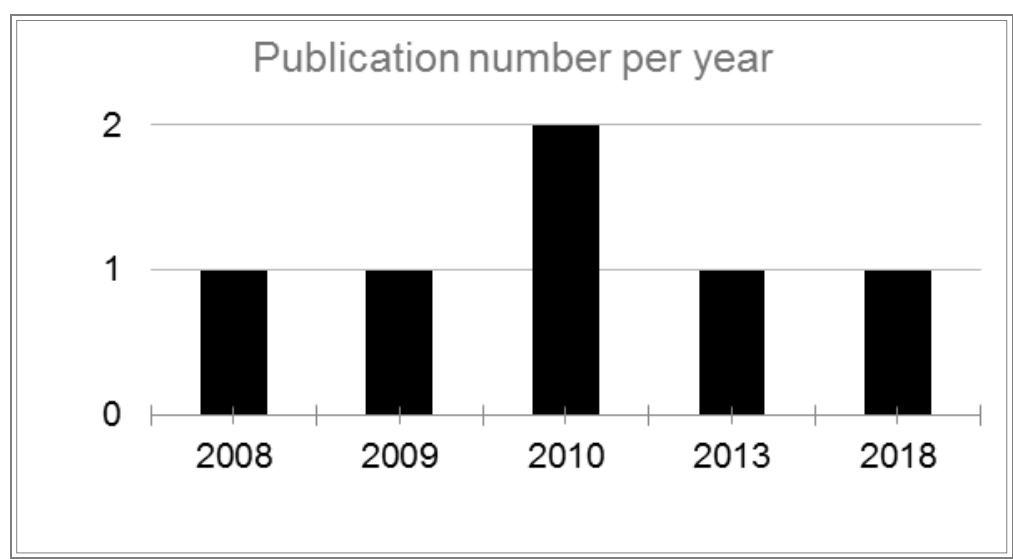

Figure 3: Statistics of the annual production of articles in the time horizon between 1999 and 2019

Besides the lack of publications in the first decade, the total of only 2 articles published in 2010 and after that only 1 article published annually, reinforces the lack of predominance of the subject in the scientific scenario. 
DOI: 10.14807/ijmp.v11i5.1280

Regarding the nature of these articles, there is a balance in this regard (Table 3). The number of conceptual and applied articles is the same over the years. Although it is expected that, firstly, conceptual articles will be published so that afterward, there will be the publication of applied articles on a certain subject, it is observed that this does not occur. From the moment that lean and metrology began to be approached concurrently, the first articles to be published were those of applied character.

The first article found at the intersection between the metrology and lean, "Getting real with Real-Time Dispatching in Metrology: an RTD solution to metrology's imperceptible cycle time impact”, is of an applied nature (BEAUMONT et al., 2008). It was not until 2010, two years after this first article was published, that the first conceptual articles on the theme appeared, “Poor metrology: The hidden cost” (CIESLINSKI, 2010) and “A Holistic Approach to Quantifying and Controlling Accuracy, Performance and Availability of Machine Tools” (WILLOUGHBY et al., 2010).

Table 3: Approach of articles

\begin{tabular}{clc}
\hline Year & \multicolumn{1}{c}{ Title } & Approach \\
\hline 2008 & $\begin{array}{l}\text { Getting real with Real Time Dispatching in Metrology; an RTD solution to metrology's imperceptible } \\
\text { cycle time impact }\end{array}$ & Applied \\
2009 & Applying lean manufacturing principles \& tools to laboratory operations & Applied \\
2010 & Poor metrology: The hidden cost & Conceptual \\
2010 & $\begin{array}{l}\text { A Holistic Approach to Quantifying and Controlling the Accuracy, Performance and Availability of } \\
\text { Machine Tools }\end{array}$ & Conceptual \\
2013 & Developing a lean measurement system to enhance process improvement & Conceptual \\
2018 & Calibration system for cost reduction: A case study in the Maquiladora industry & Applied \\
\hline
\end{tabular}

Regarding the number of citations, it is noted that the conceptual articles "A Holistic Approach to Quantifying and Controlling Accuracy, Performance and Availability of Machine Tools” (WILLOUGHBY et al., 2010), “Poor Metrology: The Hidden Cost” (CIESLINSKI , 2010) and "Developing a lean measurement system to enhance process improvement" (LEWIS; COOKE, 2013) provide a greater number of citations than the applied articles “Getting real with Real-Time Dispatching in Metrology: an RTD solution to metrology's imperceptible cycle time impact” (BEAUMONT et al., 2008), “Applying lean manufacturing principles \& tools to laboratory operations” (VINARCIK, 2009) and “Calibration system for cost reduction: a case study in the maquiladora industry“ (ARREDONDO-SOTO et al ., 2018), as seen in Table 4.

The number of citations in both databases analyzed (Scopus and WoS) is low, and there are even articles that have no citations. It was also verified that there is no co-citation 
ISSN: 2236-269X

DOI: 10.14807/ijmp.v11i5.1280

relationship between the analyzed articles, even though there are few articles found in the literature where there is an intersection between the metrology and lean.

Table 4: Number of citations per base

\begin{tabular}{|c|c|c|c|}
\hline \multirow[b]{2}{*}{ Year } & \multirow[b]{2}{*}{ Title } & \multicolumn{2}{|c|}{ Total of citations } \\
\hline & & WoS & Scopus \\
\hline 2008 & $\begin{array}{l}\text { Getting real with Real Time Dispatching in Metrology; an RTD solution to metrology's } \\
\text { imperceptible cycle time impact }\end{array}$ & 1 & 2 \\
\hline 2009 & Applying lean manufacturing principles \& tools to laboratory operations & - & 0 \\
\hline 2010 & Poor metrology: The hidden cost & - & 0 \\
\hline 2010 & $\begin{array}{l}\text { A Holistic Approach to Quantifying and Controlling the Accuracy, Performance and } \\
\text { Availability of Machine Tools }\end{array}$ & 1 & 2 \\
\hline 2013 & Developing a lean measurement system to enhance process improvement & - & 2 \\
\hline 2018 & Calibration system for cost reduction: A case study in the Maquiladora industry & - & 0 \\
\hline
\end{tabular}

Analyzing the means of publication used (Table 5), there is a predominance of articles published in conferences, with only one, "Developing a lean measurement system to enhance process improvement”, being published in a scientific journal. This journal, the International Journal of Metrology and Quality Engineering (IJMQE), is dedicated to articles that specifically address applied metrology and quality tools for industrial process improvements, with a primary focus on measurement, sensors, and instrumentation, reliability, and experimental safety, products, conformity assessment, process control, and quality management.

Table 5: Total articles published in each publication medium

\begin{tabular}{lcc}
\hline \multicolumn{1}{c}{ Means of publication } & Classification & Total of articles \\
\hline ASMC (Advanced Semiconductor Manufacturing Conference) Proceedings & Conferences & 1 \\
Design Direction - Technical Instruction and Writing, United States & Conferences & 1 \\
IPC APEX EXPO Technical Conference 2010 & Conferences & 1 \\
$\begin{array}{l}\text { Proceedings of the 36th international matador conference } \\
\text { International Journal of Metrology and Quality Engineering }\end{array}$ & Conferences & 1 \\
$\begin{array}{l}\text { Proceedings of the International Conference on Industrial Engineering and } \\
\text { Operations Management }\end{array}$ & Article & 1 \\
\hline
\end{tabular}

Regarding the nature of the conferences, it is relevant to highlight that 4 of these events have a focus on engineering and manufacturing, mainly on the analysis of mechanical and electronic systems and equipment. In your calls, there is a preference for more technical approach articles. Only the International Conference on Industrial Engineering and Operations Management has a broader coverage with diverse topics in the areas of industrial engineering and operations management. The article "Calibration system for cost reduction: a case study in the Maquiladora industry” published in this congress was categorized in the Business subarea in the annals of the event.

Looking at the number of citations by publication seen in Table 6, the article published in IJMQE has two citations in Scopus and none in WoS, since it is not indexed in this database. 
DOI: 10.14807/ijmp.v11i5.1280

Articles published at ASCM, the leading technical conference to discuss solutions that enhance the semiconductor industry's collective manufacturing experience, and the International MATADOR Conference, one of the oldest manufacturing conferences, also feature two citations at Scopus, but both also have citations in WoS and were the most cited. Both events are international and quite renowned in their respective areas.

Table 6: Number of citations by base

\begin{tabular}{lcc} 
& \multicolumn{2}{c}{ Total of Citations } \\
\cline { 2 - 3 } & Means of publication & Scopu \\
s & - & 2 \\
\hline International Journal of Metrology and Quality Engineering & 1 & 2 \\
ASMC (Advanced Semiconductor Manufacturing Conference) Proceedings & - & 0 \\
Design Direction - Technical Instruction and Writing, United States & - & 0 \\
IPC APEX EXPO Technical Conference 2010 & 1 & 2 \\
Proceedings of the 36th international matador conference & - & 0 \\
Proceedings of the International Conference on Industrial Engineering and Operations & & \\
Management & & - \\
\hline
\end{tabular}

Table 7 presents the institutions to which the articles are affiliated. Only one article was prepared through a partnership between an educational institution and a company. This article entitled “A Holistic Approach to Quantifying and Controlling Accuracy, Performance and Availability of Machine Tools” (WILLOUGHBY et al., 2010) was published in 2010 and is one of the most cited articles, as seen in Table 4. This article is associated with Machine Tool Technologies Ltda and the University of Huddersfield. The other publications are the unique and autonomous efforts of university researchers or technology companies.

Table 7: Number of Affiliate Citations by Base

\begin{tabular}{lccc} 
& & \multicolumn{2}{c}{ Total of citations } \\
\cline { 2 - 4 } \multicolumn{1}{c}{ Affiliation } & Total of publication & WoS & Scopus \\
\hline Qimonda ag & 1 & 1 & 2 \\
Design direction-technical instruction and writing & 1 & - & 0 \\
Panasonic factory solutions company of america & 1 & - & 0 \\
Machine tool technologies ltd. & 1 & 1 & 2 \\
University of huddersfield & 1 & - & 2 \\
Coventry university & 1 & - & 0 \\
Universidad autónoma de baja california & 1 & & 0 \\
\hline
\end{tabular}

Considering also the research areas indicated in the bases (Figure 4), it is possible to verify that all articles are categorized as pertinent to Engineering, corroborating with the focus of the conferences and journals to which they were submitted. The areas of Environmental Science, Decision Sciences and Business, Management, and Accounting are interposed with Engineering presenting themselves as possible subareas of application. 
DOI: $10.14807 /$ ijmp.v11i5.1280

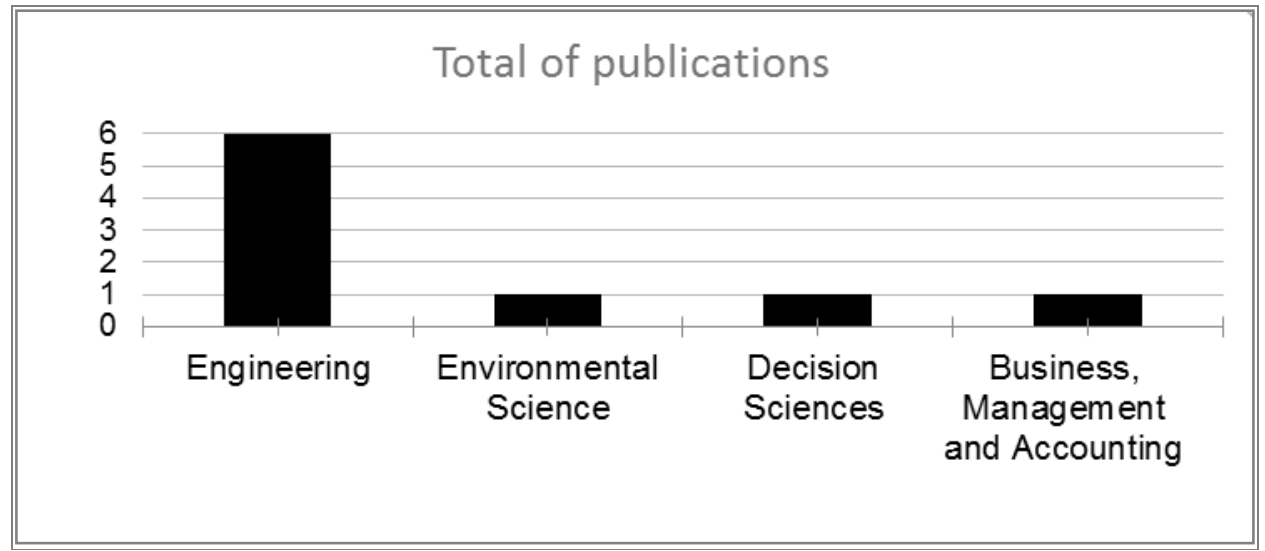

Figure 4: Total de publicação por área de aplicação

As for the place of publication of the articles in question (Figure 5), it can be seen that half of its are from the United States (United States). The remaining articles are distributed between the United Kingdom (United Kingdom) and Mexico, respectively. Since in this work are considered only articles from conferences, it should be emphasized that the term "country" refers to the nationality of the researcher responsible for the article and not the location of the event where the article was published.

Thus, the publications come from only two continents, with a substantial concentration in North America and only one publication in Europe.

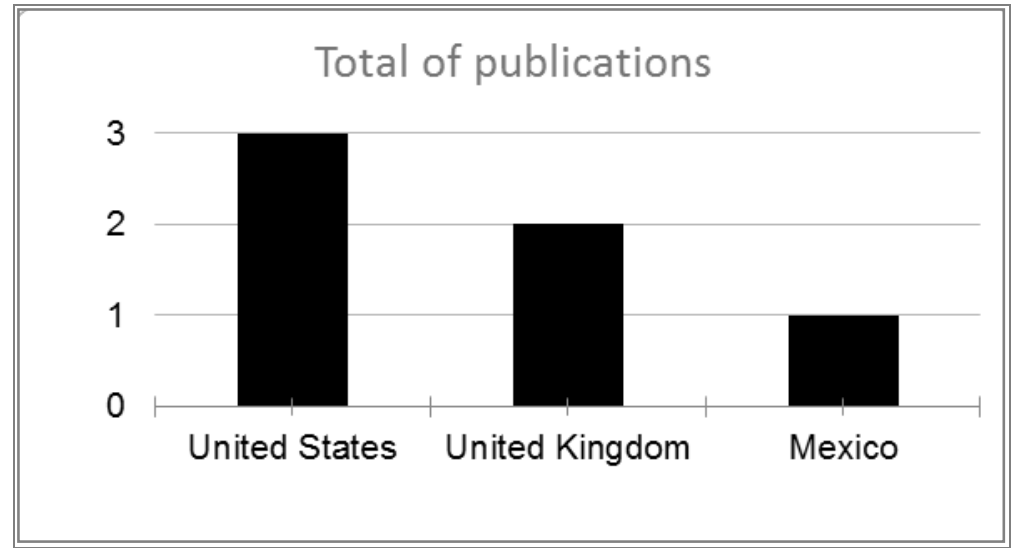

Figure 5: Total publication by country

\subsection{Qualitative analysis}

Table 8 shows the main study settings as sites where the study was applied (applied articles) or where their context was analyzed (conceptual articles).

A variety of application sites are perceived, extending between laboratories, machinery, and measurement systems. This heterogeneity is related to the various fields covered by the metrology area, which is not restricted only to places, such as companies and laboratories, but 
ISSN: 2236-269X

DOI: 10.14807/ijmp.v11i5.1280

also to equipment and machinery, techniques, systems, and processes. Thus, the results show a multitude of possibilities where lean tools and principles can be implemented.

Table 8: Application locations

\begin{tabular}{ll}
\hline \multicolumn{1}{c}{ Citation } & \multicolumn{1}{c}{ Analysis or application place } \\
\hline Beaumont et al. (2008) & Mechanical polishing process equipment in the semiconductor industry \\
Vinarcik (2009) & Metallurgical laboratory \\
Cieslinski (2010) & Internal and external metrology systems \\
Willoughby et al. (2010) & Computer numerically controlled (CNC) machine tools \\
Lewis e Cooke (2013) & Manufacturing-based measurement system \\
Arredondo-Soto et al. (2018) & Calibration laboratory of a maquiladora industry \\
\hline
\end{tabular}

Two articles with an applied approach "Calibration System for Cost Reduction: A Case Study in the Maquiladora Industry” (ARREDONDO-SOTO et al., 2018) and “Applying Lean Manufacturing Principles \& Tools to Laboratory Operations” (VINARCIK, 2009) applied tools and lean analysis in laboratories. However, while in the first the focus was on the application of tools and principles for the improvement of an existing metallurgical laboratory, the second sought to install a calibration laboratory in a company. Both in Beaumont et al. (2008) and Willoughby et al. (2010) the capacity and efficiency of equipment were the focus of the study's application. However, in the first, there was applied research, while a conceptual approach was chosen for the second. Concerning measurement systems, Cieslinski (2010) discussed the differences between internal and external metrological analysis systems in companies, while Lewis and Cooke (2013) analyzed whether, or not, lean principles can be integrated and applied in measurement systems.

So, while the study settings (application sites) are directly related to the metrology field of study or work, the tools and methods are part of the lean methodology, as shown in Table 9.

Table 9: Lean tools and principles used

\begin{tabular}{|c|c|}
\hline Citation & Tool and Principles \\
\hline Beaumont et al. (2008) & OEE, Statistical Process Control and Real-Time Dispatching (RTD) \\
\hline Vinarcik (2009) & $\begin{array}{l}\text { Value Stream Map (MFV), Quality at source, Workplace organization (5S), Batch } \\
\text { reduction, Standardization, Visual management, People involvement, Equipment } \\
\text { reliability, Leveling and time management, Value, Value flow, Continuous flow and } \\
\text { pulled production }\end{array}$ \\
\hline Cieslinski (2010) & Statistical Process Control and Lean Six Sigma \\
\hline Willoughby et al. (2010) & $\begin{array}{l}\text { Machine Performance Evaluation Optimise Monitor (MPEOM) e Total Productivy } \\
\text { Maintenance (TPM) }\end{array}$ \\
\hline Lewis e Cooke (2013) & Waste identification and elimination (seven seedlings) \\
\hline Arredondo-Soto et al. (2018) & Six Sigma DMAIC, Visual management \\
\hline
\end{tabular}

Concerning the places of analysis and application, there is also an enormous diversity among the lean tools applied, in addition to the fundamental principles of this culture that are addressed in the analyzed articles. Among the most cited tools, there are Visual Management 
INDEPENDENT JOURNAL OF MANAGEMENT \& PRODUCTION (IJM\&P)

http://www.ijmp.jor.br

v. 11, n. 5, Special Edition IFLOG 2019 - September 2020

ISSN: 2236-269X

DOI: 10.14807/ijmp.v11i5.1280

(ARREDONDO-SOTO et al., 2018; VINARCIK, 2009), Lean Six Sigma (LSS)

(ARREDONDO-SOTO et al., 2018; CIESLINSKI, 2010) and Control Process Statistics (CEP)

(BEAUMONT et al., 2008; CIESLINSKI, 2010).

The article "Applying lean manufacturing principles \& tools to laboratory operations” (VINARCIK, 2009) stands out for citing the largest number of lean tools among the 6 articles analyzed in this work, with a total of 9 tools applied. It is also worth mentioning that some of these tools are cited in the literature as the most well-known or commonly used in lean culture, such as 5S, Visual Management, and Value Stream Map (ALASKARI; AHMAD; PINEDOCUENCA, 2016; ALBLIWI; ANTONY; LIM, 2015). Also, as corroborated by Tyagi et al. (2015), this work also presented the 4 key principles of lean in an applied way: value, value flow, continuous flow, and pull production.

Still, among the most renowned tools, we highlight the Total Production Maintenance (TPM) approach (WILLOUGHBY et al., 2010), the calculation of the Overall Equipment Effectiveness (OEE) indicator (BEAUMONT et al., 2008) and applications and analyzes of the CEP (BEAUMONT et al., 2008; CIESLINSKI, 2010) present in the articles.

As for the results obtained during the application of lean tools and principles in the metrology area (Table 10), it is possible to notice that several positive results were obtained since the objectives of the applications were achieved in the articles.

Table 10: Results after lean implementation

\section{Citation}

Beaumont et al. (2008)

Vinarcik (2009)

Cieslinski (2010)

Willoughby et al. (2010)

Lewis e Cooke (2013)

Arredondo-Soto et al. (2018)

Results

Significant $16 \%$ reduction in machine cycle time, $64 \%$ decrease in the occurrence of events outside of the schedule, increase in equipment performance and increase in productivity with an $11.1 \%$ improvement in the OEE indicator. Cycle time reduction from 6 to 2 days, greater productivity with an increase from 40 to 200 requirements per month without an increase in manpower, less variation in analysis methods that allow direct comparison of data over time, reduction of 3 for less than 1 complaint per month, better quality and standardization in operations.

It enables the company to reduce costs related to inefficient measurement systems.

Providing a channel to define, establish, and maintain the required characteristics of the machine according to the rigors of the production requirement. Thus, all departments of a factory get involved to make targeted decisions about the main variables of performance, precision, and availability of machine tools, also enabling the reduction of errors.

"Proposition of a lean measurement system where an organization may be able to reduce measurement waste with simplistic changes in procedures and staff training."

The hypothesis that an internal laboratory for calibration is feasible for the company has been proven, since it results in savings from the first year of implementation and avoids payment for calibration services by an external supplier, generating a cost reduction of up to $20 \%$. Also, the processes and workspace have been standardized and controlled. 
DOI: 10.14807/ijmp.v11i5.1280

The main results obtained in the applied articles were related to the reduction of time, cost reduction, possibility of standardization of processes, and reduction of errors. In Beaumont et al. (2008), there was a $16 \%$ reduction in machine operating time due to increased availability and a significant improvement in the OEE indicator. Vinarcik (2009) also obtained a reduction of around $67 \%$ in the time of operation, which increased the productivity of the process by about 500\%. In Arredondo-Soto et al. (2018) there was a 20\% reduction in costs related to the calibration process after the installation of an internal laboratory managed by lean principles.

When analyzing the results obtained in the articles of the conceptual approach, it appears that they corroborate with the results achieved in the applied articles. Lewis and Cooke (2013) prove the possibility of reducing errors and waste when analyzing measurement systems from a lean perspective, while Cieslinski (2010) states that metrology done correctly can also reduce costs, especially those related to errors. Willoughby et al. (2010) establish that the application of a lean tool and TPM principles can reduce errors and increase machine availability.

Also, the difficulties and facilitators pointed out by the authors during the implementation phase of the works where the techniques were applied were analyzed. In the conceptual articles, these difficulties or facilitators were only identified as possible. As none of the articles exposed to facilitating aspects, Table 11 presents only the difficulties encountered.

Table 11: Difficulties found

\begin{tabular}{lc}
\hline \multicolumn{1}{c}{ Citation } & Difficults \\
\hline Beaumont et al. (2008) & - \\
Vinarcik (2009) & Customer resistance to change \\
Cieslinski (2010) & Lack of metrology knowledge \\
Willoughby et al. (2010) & Machine tools are complex systems \\
Lewis e Cooke (2013) & - \\
Arredondo-Soto et al. (2018) & - \\
\hline
\end{tabular}

Among the articles with an applied approach, only "Applying lean manufacturing principles \& tools to laboratory operations" pointed out an implementation difficulty. Despite the resistance to changes on the part of the employees being regularly pointed out as a difficulty of lean implementation, Vinarcik (2009) pointed out the resistance of the clients to the alteration of some documents and the change in some procedures as the main obstacle found by him during the execution of your work.

In Cieslinski (2010), the lack of mastery related to metrology concepts revealed a difficulty in carrying out his analyses. And Willoughby et al. (2010) defined the operational complexity of some equipment as possible difficulty in applying the Machine Performance 
Evaluation Optimize Monitor (MPEOM) for the success of the TPM approach in some companies.

Finally, due to the noticeable lack of intersection between the metrology and lean in the literature, we sought to find in the analyzed articles possible motivations for carrying out these studies, as seen in Table 12. Only the article "Poor metrology: The hidden cost” (CIESLINSKI, 2010) did not determine a clear motivation for carrying out its analysis.

Table 12: Factors that motivated lean implementation

\begin{tabular}{ll}
\hline \multicolumn{1}{c}{ Citation } & \multicolumn{1}{c}{ Factors that motivated the analysis } \\
\hline $\begin{array}{l}\text { Beaumont et al. (2008) } \\
\text { Vinarcik (2009) }\end{array}$ & $\begin{array}{l}\text { Reduce cycle time and increase performance of equipment involved in the process } \\
\text { Understand the impacts of lean principles and their tools in a laboratory }\end{array}$ \\
$\begin{array}{l}\text { Cieslinski (2010) } \\
\text { Willoughby et al. (2010) }\end{array}$ & $\begin{array}{l}\text { Understand how lean principles can simplify areas of metrology related to machines and tools } \\
\text { Lewis e Cooke (2013) }\end{array}$ \\
$\begin{array}{l}\text { Urgency in the control of measurement systems in an industrial context } \\
\text { Arredondo-Soto et al. (2018) }\end{array}$ \\
$\begin{array}{l}\text { Reduce costs in the payment of calibration services, administration of measurement } \\
\text { equipment train personnel in the implementation of a metrology culture }\end{array}$ \\
\hline
\end{tabular}

The understanding of the impacts of lean implementation on systems, laboratories or measurement equipment was cited by both Vinarcik (2009) and Willoughby et al. (2010) as motivation for their work. However, both articles have a completely different approach, since “Applying lean manufacturing principles \& tools to laboratory operations” carried out an applied study in a real laboratory, “A Holistic Approach to Quantifying and Controlling the Accuracy, Performance, and Availability of Machine Tools" proposed analysis of a conceptual model. It is also worth mentioning that both works have a focus on lean, where the metrology area is seen only as a field of application to be explored.

In contrast, the motivations set out in "Calibration system for cost reduction: A case study in the Maquiladora industry”, “Getting real with Real-Time Dispatching in Metrology: an RTD solution to metrology's imperceptible cycle time impact" and "Developing a lean measurement system to enhance process improvement” are more related to problems identified in the processes and operations of the objects of their analysis, thus having specific objectives and more focused in the field of metrology. The main motivation of Arredondo-Soto et al. (2018) was to reduce operating costs of a company's calibration processes, Beaumont et al. (2008) describe problems with a measuring equipment that needs to be better used and Lewis and Cooke (2013) address the urgency in controlling the measurement system in an industrial context. Thus, these articles seem to use lean implementation only as a way to achieve their results. 
DOI: 10.14807/ijmp.v11i5.1280

\section{CONCLUSIONS}

This study was conducted, systematically with the support of the PRISMA Protocol, to answer the research question of whether there is an intersection between the areas of metrology and lean in the scientific literature. To this end, the WoS and Scopus databases were analyzed in the last 20 years.

The search protocol allowed to identify only 6 articles that addressed the intersection between the areas, thus evidencing a huge field for conducting research, both conceptual and applied.

Among the 6 articles analyzed, only 1 article was published in a journal, and the others originate from international conferences. The maximum number of citations that the articles presented was 3, considering the sum of citations from the analyzed databases. Only the United States, Mexico, and the United Kingdom published. Therefore, the scientific literature needs more robust and relevant studies addressing lean and metrology, a contribution from other countries, a collaboration between countries, institution-company and institution-institution to leverage the intersection between lean and metrology in the scientific field.

The limitations found in this article are the language, as it only covered articles in English and the use of only two databases: WoS and Scopus. As suggestions for future work, the study will cover all journals and databases within the Capes Journal Portal once it grants access to over 45 thousand national and international journals.

\section{ACKNOWLEDGMENTS}

This work was carried out with the support of the IFRJ/Nilópolis. The authors of the project are grateful to IFRJ for the scholarships granted and for supporting the Development of Brazilian Scientific Research.

\section{REFERENCES}

ALASKARI, O.; AHMAD, M. M.; PINEDO-CUENCA, R. (2016) Development of a methodology to assist manufacturing SMEs in the selection of appropriate lean tools, International Journal of Lean Six Sigma, v. 7, n. 1, p. 62-84. doi: 10.1108/IJLSS-02-20150005.

ALBLIWI, S. A.; ANTONY, J.; LIM, S. A. H. (2015) A systematic review of Lean Six Sigma for the manufacturing industry, Business Process Management Journal, v. 21, n. 3, p. 665-691. doi: 10.1108/BPMJ-03-2014-0019.

ARREDONDO-SOTO, K. C.; CARRILLO-GUTIÉRREZ, T.; QUINTEROS, M. M. S.; AVILA-LOPEZ, L. A. (2018) Calibration System for Cost Reduction: A Case Study in the Maquiladora Industry, In: International conference on industrial engineering and operations management. Proceedings... Bandung, Indonesia: IEOM Society International, 2018. 
BAI, C.; SATIR, A.; SARKIS, J. (2019) Investing in lean manufacturing practices: an environmental and operational perspective, International Journal of Production Research, v. 57, n. 4, p. 1037-1051. doi: 10.1080/00207543.2018.1498986.

BALZER, W. K.; FRANCIS, D. E.; KREHBIEL, T. C.; SHEA, N. (2016) A review and perspective on Lean in higher education, Quality Assurance in Education, v. 24, n. 4, p. 442-462. doi: 10.1108/QAE-03-2015-0011.

BALZER, W. K.; BRODKE, M. H.; KIZHAKETHALACKAL, E. T. (2015) Lean higher education: successes, challenges, and realizing potential, International Journal of Quality \& Reliability Management, v. 32, n. 9, p. 924-933doi: 10.1108/IJQRM-08-2014-0119.

BARRADAS, J.; SAMPAIO, P. (2017) ISO 9001 and ISO/IEC 17025: Which is the best option for a laboratory of metrology? The Portuguese experience, International Journal of Quality \& Reliability Management, v. 34, n. 3, p. 406-417. doi: 10.1108/IJQRM-03-20140032.

BEAUMONT, P. L.; GOAD, A.; PERIRA, D.; QUIMONDA, A. G.; RICHMOND (2008) Getting Real with Real Time Dispatching in Metrology; an RTD Solution to Metrology's Imperceptible Cycle Time Impact, In: ADVANCED SEMICONDUCTOR MANUFACTURING CONFERENCE. Proceedings... Cambridge, MA, USA: IEEE, 2008, p. 311-317. doi: 10.1109/ASMC.2008.4529060.

CIESLINSKI, M. (2010) Poor Metrology: The Hidden Cost, In: IPC APEX EXPO TECHNICAL CONFERENCE. IPC Printed Circuit Expo, APEX \& Designer Summit Proceedings... 2010, p. 7.

CISNEROS, L.; IBANESCU, M.; KEEN, C.; LOBATO-CALLEROS, O.; NIEBLAZATARAIN, J. (2018) Bibliometric study of family business succession between 1939 and 2017: mapping and analyzing authors networks, Scientometrics, v. 117, n. 2, p. 919-951, doi: 10.1007/s11192-018-2889-1.

COSTA, D. F.; CARVALHO, F. M.; MOREIRA, B. C. M.; PRADO, J. W. (2017) Bibliometric analysis on the association between behavioral finance and decision making with cognitive biases such as overconfidence, anchoring effect and confirmation bias, Scientometrics, v. 111, n. 3, p. 1775-1799. doi: 10.1007/s11192-017-2371-5.

FILSER, L. D.; SILVA, F. F.; OLIVEIRA, O. J. (2017) State of research and future research tendencies in lean healthcare: a bibliometric analysis, Scientometrics, v. 112, n. 2, p. 799 816. doi: 10.1007/s11192-017-2409-8.

GOMEZ, M.; KREMER, R.; SLEPETIS, C. (2017) Metrology in the National Agricultural Technology Institute (INTA), In: 18TH INTERNATIONAL CONGRESS OF METROLOGY. Proceedings... Paris, France: EDP Sciences, 2017, p. 01008. doi: 10.1051/metrology/201701008.

INMETRO (2019) Sistema de Consulta aos Escopos de Acreditação dos Laboratórios de Calibração Acreditados segunda a ABNT NBR ISO/IEC 17025, Rede Brasileira de Calibração.

KARTHIYAYINI, N.; RAJENDRAN, C. (2017) Critical factors and performance indicators: accreditation of testing- and calibration-laboratories, Benchmarking: An International Journal. doi: 10.1108/BIJ-04-2016-0058.

KOSKELA, L.; FERRANTELLI, A.; NIIRANEN, J.; PIKAS, E. (2019) Epistemological Explanation of Lean Construction, Journal of Construction Engineering and Management, v. 145, n. 2, p. 04018131. doi: 10.1061/(ASCE)CO.1943-7862.0001597. 
KOVACEVIC, M.; JOVICIC, M.; DJAPAN, M.; ZIVANOVIC-MACUZIC, I. (2016) lean thinking in healthcare: review of implementation results, International Journal for Quality Research, v. 10, n. 1. doi: 10.18421/ijqr10.01-12.

LEITE, H. R.; VIEIRA, G. E. (2015) Lean philosophy and its applications in the service industry: a review of the current knowledge, Production, v. 25, n. 3, p. 529-541. doi: 10.1590/0103-6513.079012.

LEWIS, P.; COOKE, G. (2013) Developing a lean measurement system to enhance process improvement, International Journal of Metrology and Quality Engineering, v. 4, n. 3, p. 145-151. doi: 10.1051/ijmqe/2013058.

MOHER, D.; LIBERATI, A.; TETZLAFF, J.; ALTMAN, D. G. (2009) Preferred reporting items for systematic reviews and meta-analyses: The PRISMA statement, PLoS Med, v. 6, n. 7. doi: 10.1371/journal.pmed.1000097.

MONGEON, P.; PAUL-HUS, A. (2016) The journal coverage of Web of Science and Scopus: a comparative analysis, Scientometrics, v. 106, n. 1, p. 213-228. doi: 10.1007/s11192-015-1765-5.

PEDRAZA, N. A. P.; MONTEALEGRE, J. I. P.; SERREZUELA, R. R. (2018) 'Feasibility Analysis for Creating a Metrology Laboratory Serving the Agribusiness and Hydrocarbons in the Department of Huila, Colombia', International Journal of Applied Engineering Research, v. 13, n. 6, p. 3373-3378.

RAUCH, E.; DAMIAN, A.; HOLZNER, P.; MATT, D. T. (2016) Lean Hospitality Application of Lean Management Methods in the Hotel Sector, Procedia CIRP. (Research and Innovation in Manufacturing: Key Enabling Technologies for the Factories of the Future - Proceedings of the 48th CIRP Conference on Manufacturing Systems), 41, p. 614-619. doi: 10.1016/j.procir.2016.01.019.

SARHAN, J.; XIA, B.; FAWZIA, S.; KARIM, A. (2017) Lean construction implementation in the Saudi Arabian construction industry, Construction Economics and Building, v. 17, n. 1, p. 46, doi: 10.5130/AJCEB.v17i1.5098

SILVA, C. C. M.; AROUCHE, M. N. M.; LIMA, Z. M.; VIEIRA, A. C. S.; PINHEIRO, E. M. (2019) Application of lean manufacturing tools: a case study in a mattress factory, Journal of Lean Systems, v. 4, n. 1, p. 87-104.

SILVA, V. V. M.; RIBEIRO, J. L. D. (2019) Obtaining laboratory accreditation - required activities, International Journal of Health Care Quality Assurance, v. 32, n. 1, p. 71-83. doi: 10.1108/IJHCQA-10-2017-0191.

TUNGER, D.; EULERICH, M. (2018) 'Bibliometric analysis of corporate governance research in German-speaking countries: applying bibliometrics to business research using a custom-made database’, Scientometrics. doi: 10.1007/s11192-018-2919-z.

TYAGI, S.; CAI, X.; YANG, K.; CHAMBERS, T. (2015) Lean tools and methods to support efficient knowledge creation, International Journal of Information Management, v. 35, n. 2, p. 204-214. doi: 10.1016/j.ijinfomgt.2014.12.007.

VINARCIK, E. J. (2009) Applying Lean Manufacturing Principles \& amp; Tools to Laboratory Operations’, In: Sae World Congress \& Exhibition, Proceedings... doi: 10.4271/2009-01-1191. 
WESTGARD, J. O.; WESTGARD, S. A. (2017) Six Sigma Quality Management System and Design of Risk-based Statistical Quality Control, Clinics in Laboratory Medicine, v. 37, n. 1, p. 85-96. doi: 10.1016/j.cll.2016.09.008.

WILLOUGHBY, P.; VERMA, M.; LONGSTAFF, A. P.; FLETCHER, S. (2010) A Holistic Approach to Quantifying and Controlling the Accuracy, Performance and Availability of Machine Tools, In: 36TH International Matador Conference. Proceedings... London: Springer London, p. 313-316. doi: 10.1007/978-1-84996-432-6_71.

YAN, Y.; LIAO, Z.; CHEN, X. (2018) Fixed-income securities: bibliometric review with network analysis, Scientometrics, v. 116, n. 3, p. 1615-1640. doi: 10.1007/s11192-0182800-0. 